\title{
Towards Place-Sensitive Urban Interventions: An Examination of the Significant Characteristics of Place in Selected Urban Nodes in Colombo
}

\author{
Amanda Rajapakse and Ranjith Dayaratne
}

\begin{abstract}
"Place" is a concept that has received recent attention among architects, planners and urban designers. It is seen as a useful concept to examine and to be employed for planned interventions in the built-environment. Place is a spatial entity as well as a social-psychological entity. Its characteristics therefore are intertwined with these aspects. What are the significant refinements of these characteristics that will elevate the quality of places and transform them to memorable cherished places? This was a research question that prompted an inquiry into the urban spaces whereby an attempt was made to recognize and emphasize the significant characteristics of place that will enable place-sensitive planned interventions in the city. The study based in Colombo examined in detail the characteristics of two selected places that mark them special and significant. The study proposes a theoretical construct of those characteristics that must be enhanced in planned interventions.
\end{abstract}

\section{Introduction}

"To be human is to live in a world that is filled with significant places: to be human is to have and to know your place".

Martin Heidegger (1960:19)

Place is a rudimentary concept in the life of a human being. It reveals the external bonds of a person's existence, and is a profound and complex aspect of his or her experience of the world. The presence of significant places in a city not only enhances the quality of the city but also the life of the city dwellers. Indeed, the livability of a city and its identity are given expression by the nature and extent to which such places are present in an urban landscape. Nevertheless, it is a concept that has been given little attention by both planners and architects in their contemporary practice. We seem to have a meager understanding of the constituents of place, their ramifications and the ways in which we experience them, despite the fact there is a strong argument for making "place" the central focus in our planned interventions both in planning as well in architecture.
A city or an urban millieu is unquestionably a place in which the architects and the planners act. The urban planners and architects are constantly grappling with such places and their interventions determine the way in which urban places are generated, sustained and experienced. It is not unfair to demand then that our planning and architectural concepts must stem from "place" and be sensitive to the nuances of places that are already present. This paper discusses the idea of place in the context of urban interventions and proposes ways of making our urban interventions more place-sensitive, placespecific place-enhancing and placegenerating.

\section{A Model For the Examination Of Characteristics of Place}

Architecture and planning are tools employed to manipulate the environment, and human experience and thereby people's actions. In this sense Architecture and Planning are powerful change agents intervening in the generation and sustenance of human experience which is undeniably 
hinged to the idea of place. Therefore, how they are so employed matters a great deal, for those who are concerned with people and places. In fact, it has been demonstrated that the rudimentary role of architecture and planning are to enable healthy places (Schultz, 1980; Alexander, 1987; Meiss,1990; Dayaratne, 1992), and all design and planning interventions must stem from this objective. Nevertheless, the relationship of the concepts of place to architecture and planning, have largely been undervalued and only occasionally and intermittently applied in real practice. In other words, we do not seem to have a commonly shared theoretical orientation among the design and planning professions that recognise and reinforce the intrinsic qualities of place, whereby human experiences and human actions are sensitively and meaningfully intervened. Despite the fact that both Phenominologists ${ }^{1}$, and psychologists from time to time have attempted to define place in their relationship to Architecture and planning (Schultz,1980, Canter, 1977), they still remain only marginally influential in contemporary practice.

Indeed, the phenomenological inquiries stem from the works of Heidegger who recognized the existence of Man and his being, as inseparable from the place in which he exists. The approach to studying people and places as they are, known as "Phenomenology" according to Husserl (1962) and defined as the 'science of being' is central to this understanding. Norberg Schulz (1980) recognising the value of phenomenology, made a connection through it to architecture signifying the value of the idea of place to design practice. Others such as Ralph (1976) have followed the theoretical orientations of phenomenology in establishing a theory on the concept of place as relevant to planning. Tuan (1977) among many others examines place from a geographical experiential perspective, while Canter (1977) explores place as a psychologically endowed entity.

According to Canter (1977), place could be conceived as an overlap among physical, social, and psychological systems. A place is constituted of Physical Attributes (Physical), Activities, (Social) and, Conceptions (Psychological) (See Fig .01). Notable here is the manner in which these components are inter related, constituting a series of dialectics that form a common structure.

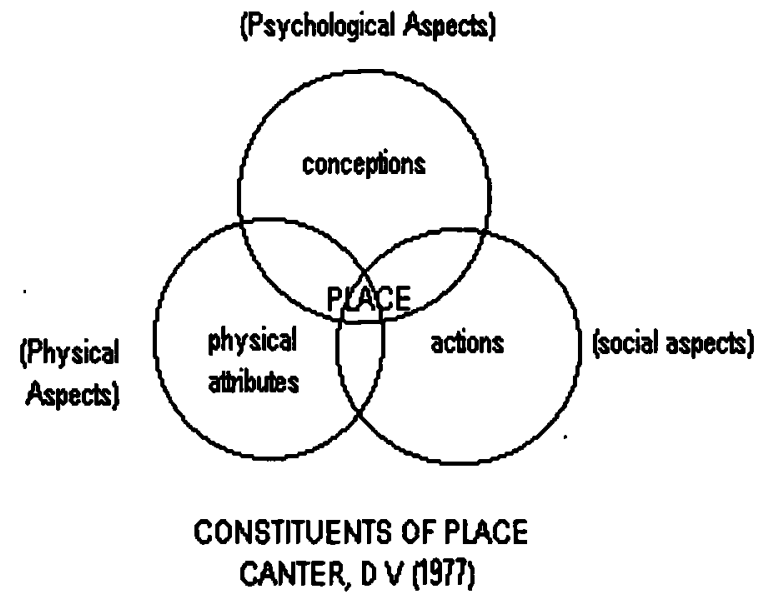

' These constitute mainly architects, planners, and

The model offered by Canter (1977) geographers interested in the qualitative and everyday transactions between environments and people. is found to be useful to understand the three characteristics of places, although there are most certainly specific weaknesses in this 
model. For instance, according to this model, a place is at the interpolation of the three constituents and thus denies. the existence of place outside this overlap. It cannot thus be employed to explain the mythical or conceptual places which exist only in the minds of people and not."real" (physical). Indeed this model is applicable only at one level of the existence of the place $^{2}$.

\section{The Study}

Nevertheless, it is felt that it is useful to employ this model if only to map out the areas of inquiry of characteristics of place. Thus, with this understanding and the model of place in mind, a study was conducted examining two selected places in the suburbs of Colombo city. The two places. were chosen for their overriding characteristics aligning with' two constituents of place as outlined in this model; namely Physical aspects and Social aspects. Employing the phenomenological mode of inquiry, the researcher by means of empathising with place elucidated the essentially significant characteristics of each place. Having been selected, each place was studied in terms of all the three aspects whereby an attempt was made to build up a "profile of the place: a holistic portrait, which then was analysed to recognise what particular attribute of these characteristic contributed to the significance of the place.

\section{THE GALLE FACE GREEN:}

\section{The Place- 01}

The Galle Face Green needs little or no introduction to the Sri Lankans, for it is so well known and built into the psychic of them as the singlemost real public "open" space in Colombo. Located close to the city centre sandwitched between the sea and the Colombo-Galle Road, from which possibly its name is derived, this is a vast track of open flat land accessible to all public almost all the time. Thus it is a place of enormous significance to the city dwellers of Colombo as a place for "recreation", and at the same time to the visitors from the hinterland to the city as the place to "encounter the sea" and gain a significant component of the "experience of Colombo". To the many school children whose first school trip away from home, and to others visiting Colombothe capital of Sri Lanka, a visit and an imersion in the experience of Galle Face is considered essential if not central.

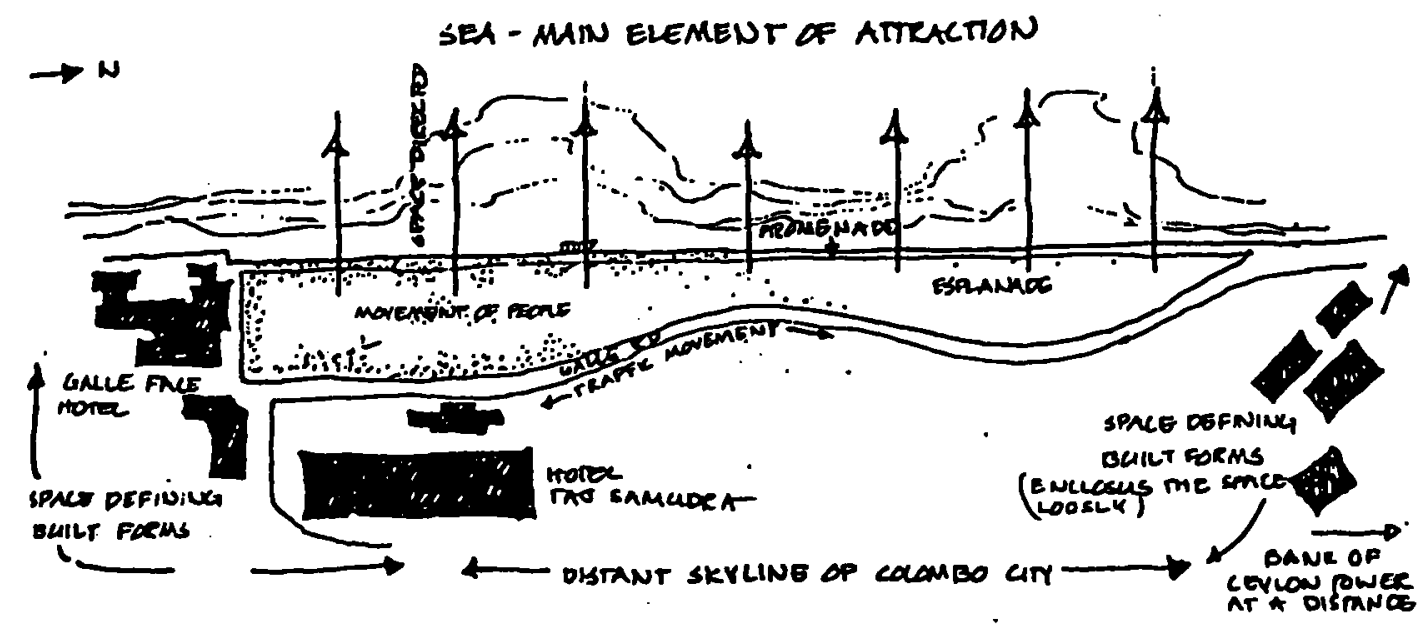

${ }^{2}$ Place exists at a number of levels. For a discussion

Figure 2:

see Tuan Yi Fu (1977), Dayaratne (1992)

The Singlemost Public Open Space in the city 
What are the essential characteristics of this unique place and what implications would such an understanding offer for a design and planning intervention?

\section{The Characteristics}

The characteristics of any place cannot be captured except as experiential entities. The semantics one may employ to describe any characteristic whether physical or social indeed are experiential and therefore are also psychological. Thus in this study, no attempt is made to segregate the psychological characteristics since they become almost inseparable both in the inquiry and its presentation.

\section{The Physical Attributes}

Galle Face green is "a large open space" "borderin intensly built-up" urban areas of the city of Colombo. As a predominantly "naturally created" place, the significant presence of it is not derived from man made physical demarcations, enclosures etc, but as an aesthetic gesture of simple and natural elements. In the case of Galle Face, its elements, "the defining vast expanse of water" the "vast open space", (which functions as a forecourt to the sea) and the sky create its sense of place and its significance.

It was revealed that Galle Face green has remarkable physical characteristics that make it special, and they can be summed up as follows.

- (scale) It's sudden grand voluminous whole and it's vastness and boundlessness, as experienced through the immediate appearance from a densely packed built area, functions as a breathing space.to which one is released on to.

- (visual definition) The level at which a person perceives the water.

- (topography and Visual Scope) Unlike at most other beach areas around, at Galle Face the sea is experienced at a higher elevation, increasing the visual scope and perception of a larger, voluminous space, which appears as majestic' and dominating. A sense of exhilaration and exposure could be felt and this sense overwhelms the dweller of this place.

- (Definition) The esplanade bordering the sea, forms a strong edge to it, where a strong separation is felt between the two elements, (land and sea) "accentuating" each other's quality. It also functions as a stage set supporting the social life that goes on among people, and the continuing events related to aesthetics of the changing natural beauty of the sea.

Galle Face is the result of an intelligible composition of distinct natural and man made elements. Through the "interaction" of the "ground surfaces" of the esplanade, "water" and "sky", the natural characteristic totality of place is formed, which constitutes the basic elements of landscape. The resultant spirit of place has come about through the expression of these elements namely, water, esplanade (ground) and sky.

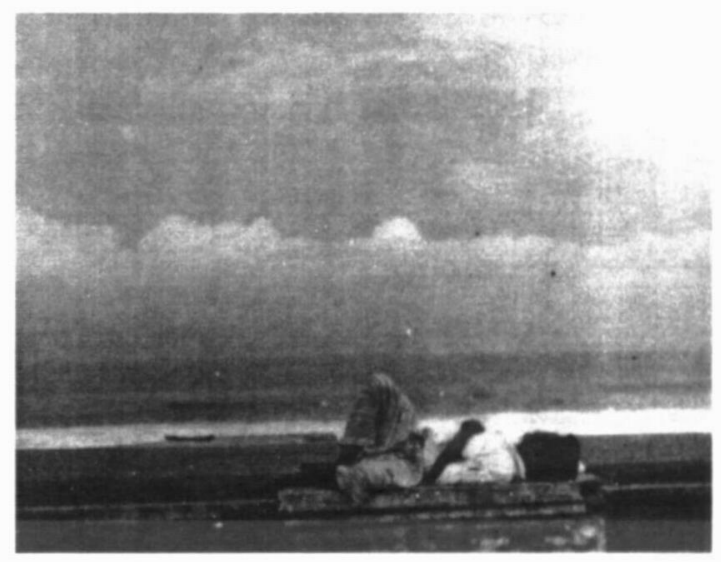

Figure 3: Experiencing the Exoticness

At Galle face, the sea is experienced as "embodying an eternal order centered on one's self". The vast expanse of sky, it's "relationship to water and ground", as it is experienced from the esplanade, appears in an "all embracing grandiose". The "changing colours and hues" of the sky is that which elevates the quality of place through the "reflecting water of the sea". 
The "sky is high", and embraces the "simultaneously continuos water", with it's colourful splendor during different times of the day. It does not however possess the absolute quality of the water body, it is viewed as a perfect union which brings out the wondrous exoticness to the place.

\section{The Activities}

The activities within the place changes with it's varying dynamism, during different times of the day. In a space as singular as the Galle Face green, it has been possible to create a multitude of settings, each with it's appropriate poetics. The diversity set within an urban frame work and unified with it's persuasive, romantic and naturalistic themes, creates an ideal setting for public activities._Galle face is a place where one single dominating natural element could bring a variation of society to socialize in the same context. The social vibrance could be observed to different degrees during different times of the day. For example- in the early mornings, the atmosphere within the setting is calm, cooling and peaceful, and this encourages a certain social class of city dwellers (largely high income category) to rub shoulders with a similar group of people.

The simple social intercourse created when people rub shoulders in public, is one of the essential kinds of social glue in society. They come for leisure activities such as -exercising, jogging, etc.(routine activities). This becomes the place for having casual conversations. In fact. apart from these people who use the inner periphery of the green (the promenade) the esplanade is generally isolated. ${ }^{3}$

During the afternoons, Galle face is a "dead" place. The heat of the sun, and perhaps the dull and static landscape does not create a suitable setting for gathering and thus it remains socially abandoned. In contrast, during the evenings, Galle face

\footnotetext{
${ }^{3}$ No other supportive activities (such as mobile food parlors, ice cream stands, etc) could be observed during this time of the day.
}

takes a totally different social dynamism. This is the time of day when the Galle face esplanade is most colourful. It functions as a nucleus of activity where various numerous social activities are nucleated and diversified. Mainly, families or groups of people occupy different locations, where territories are marked and occupied by them. These define smaller places within the larger context of the esplanade. Variety in activity such as, mobile food stands, balloon sellers, gram sellers etc. could be seen within the vicinity. They are the many small-scale commercial activities which support public life. They provide points of anchor for people to mark their territories around. While these food stands add colour and life to the setting, they are also the routine activities that certain people attend to in order to earn a living.The late evenings bring out a different set of people to the Galle Face Green. They are mainly younger crowds who come in 'gangs', by vehicles, to booze, dance and have fun. Specially during weekends these gangs could be observed until early hours of the following morning.

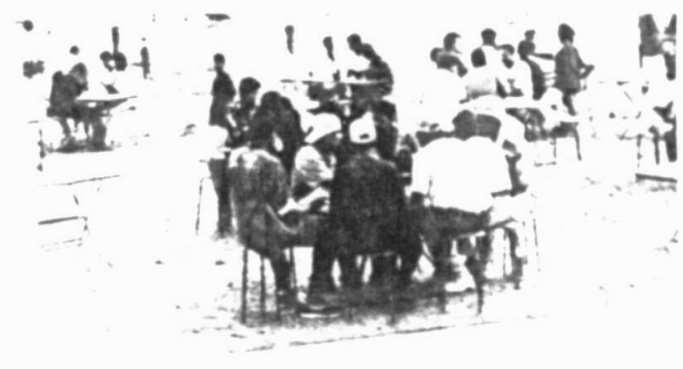

Figure 4. Variety of Social Presence

This powerful, aesthetically dominating element is capable of evoking strong, common meanings related to it's beauty across cultures and people. The dramatic view of the sea, the cool breeze, and it's vast and boundless space with the dynamic environmental quality, evokes an emotional upliftment, a dynamic sensation, within the person. This contrasting beauty of natural elements within a dense urban setting, creates diverse experiences in the day to day life of the urbanite. The natural interrelated elements express fundamental aspects of being. Thus, this kind of experience within the urban setting is not a 
mere flux of phenomena, it has structure, and embodies meaning, which could vary from simple functional meanings to valued more symbolic meanings.

Indeed, Galle Face is meaningful for the thousands of urbanites who are trapped in the pressures of day today life. Galle face is such a place which provides refuge to those who seek such refuge.There are very powerful perceptual meanings too, generated by the setting, which are capable of fulfilling the senses of a human being to it's fullest, and to a complete state of being

The perceptual meanings generated visually are due to people, their colourful clothing, changing colours of the sky etc. Aurally the sound of crashing waves against the shore, continuous rhythmic sound of the blowing wind and other sounds such as the chattering of people in a joyous manner, cacohpony of tooting horns of the ice-cream vans, loud verbal advertising of the gram/balloon sellers creates a dynamic setting within the place. Olfactory cues such as the strong, salty smell of the sea, which is mixed with the aroma of varieties of food, enhances the human use of the place, giving meaning to the setting.

The anchorage of these vibrant social activities and indeed the sea and its presence of the expanse complimented by the spatial expanse available adjoining in the geographic setting. Lack of any vegetation enhances this presence of the expanse and provide the atmosphere to the dweller to take part in making a great place in the city, providing the anchor for a good social life the people so desperately want to maintain.

During the late evenings people using the esplanade appear as a background silhouted against the sky, which is sometimes gently undulating, sometimes wild and serrate. In this landscape, the person becomes secondary. It is a place where people reach out to the natural aesthetic element.

The man made structures contribute very little in enhancing the naturally exotic place of Galle Face. The surrounding buildings such as the Taj samudra from the East, Galle Face Hotel from the South, the hotel marriot and Hilton as well as the bank of Ceylon building from the North do not define the esplanade sufficiently. They do not offer continuity nor scale to be experienced as an enclosure. Thus the boundary of the esplanade is only thinly visible as a beginning of an enclosure. However, the linear space allocation for the esplanade increases the visual scope of the sea, thus the sea could be viewed as the dominant force of attraction towards which the space of the esplanade is attached to.

Indeed, what is significant here is that the "exotoc" natural elements" collectively make up a very strong sense of place. This sense of place offers its manifestation in three particular areas distinctly present within it. The "high speed journey" available along the "Galle Road, (almost straight and defining its land edge), the "stroll walk" available along the not. so defined track along the higher elevation at the edge of the sea, and in sharp contrast to these, the "settled and paused "being in" possible in its central land mass.

\section{The Nugegoda Stretch Place 02}

The study focussed upon the stretch of Stanley Thillekeratne Mawatha, from the Bo-tree junction to the Super market area; a space dominated by social activities. ${ }^{4}$ It functions not only as a transport link, but also as a service area to the city which accommodates almost every type of shopping activity ranging from, groceries, to textiles, pharmacies, bookshops, jewelry shops, etc. Again an area that needs little introduction at least for the Urban dwellers of the Colombo city.

\section{Physical Attributes}

The physical formation itself is a notable significant guise in the social experience of Nugegoda.

\footnotetext{
${ }^{4}$ (As the social life, and formation of space is stream lined in two directions).
} 
For example,

- The narrow, linear, stretch of road, opening onto two expanded, larger nodes on either side.

- The Bo tree junction, with the Bo tree as a landmark on the West end.

- The super market junction -with the opening up on to a larger square/breathing space, on the East end. facades, and encloses the space of the street loosely.

\section{The Activities}

The activities of the place is dominated by people and vehicles equally. In fact, the "automobile is a dominating entity" at Nugegoda. This particular stretch being narrow, the traffic between the nodes has created a "dense vehicular presence" impinging upon the positive physical growth and character of this place.

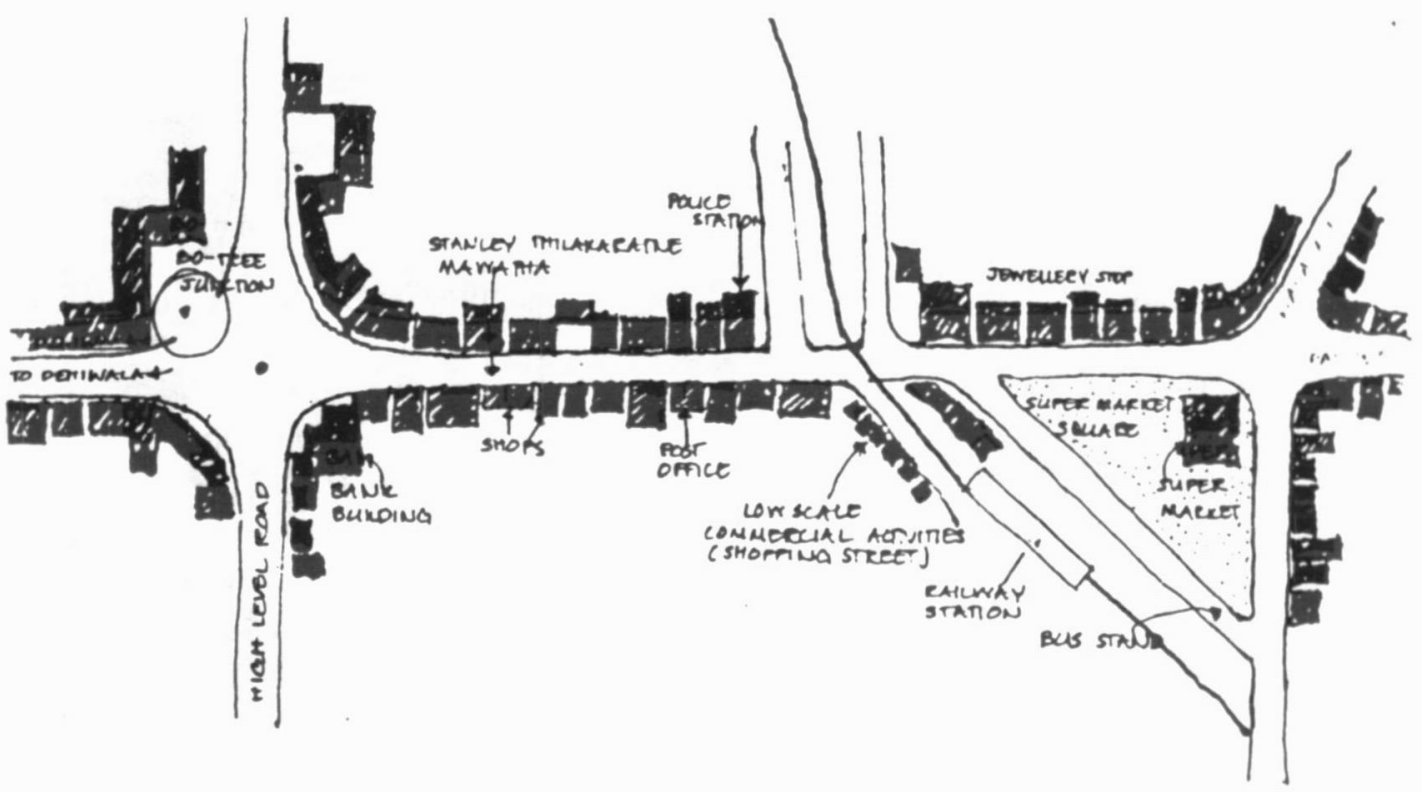

Figure 5: Map of the Area.

From the Bo-Tree Junction to the Super Market

These aspects bring about legibility and identity to the place. Yet, there is a decrease in the vividness of impressions of the physical experience along the street. This is due to the fact that the space is "linear along one straight stretch". The physical formation of the street is in the "dense packing of shops with narrow frontages" defining the edge projecting a very "strong urban character". The smaller divisions "humanize" the urban fabric. The building formation is "single to three stories in height". Due to the language used, and formation of the above, the variation experienced as one walks along the street is "uninteresting" to the dweller. Although the built fabric is varied in scale and height, it lacks continuity in the detailing of it's
The links to transportation nodes however also induces a high pedestrian movement along the street. The shopping activities on both sides of the street "generate" and make up the predominant activity; movement of people. However, the sidewalks are "narrow" and prevent free movement of people and therefore the movement of people is "slow and disturbed". Spaces along the side-walks absorb and contribute to life. A spill over of the pedestrians could be observed along the vehicular street, adding to the traffic problem. Thus the journey through the shopping street is a "struggle", and is reported a "grueling experience" in this respect. Although "chaotic and disorganized" as a result, it is important to understand, that certain wider-spots along the street define spaces to walk, to pause, to change direction etc. The "linearity" of the physical formation however predominantly 
suggests movement along it's linear passage although the physical setting does not provide the facility to conveniently do so.

The physical formation of the space, especially towards "the super market end, has provided the base" to reinforce the social focus further. "It establishes a hierarchy in the spatial formation too.

For example, the narrow, tight physical formation of the street, opens out into a "larger square" in front of the Railway station facing the super market. Which has now become a car park. Its' openness has however been diffused by 'shining steel tops' of a large numbers of cars. The location and formation of the super market also reduces the importance of the square. Further, its "drab and monotonous mass" and its "inward looking individualistic character" neither respect, nor strengthen the open space in front. The railway station with its "back" against the open space also reduces the intensity and sociability of the entire square, as it does not invite people into the space at all.

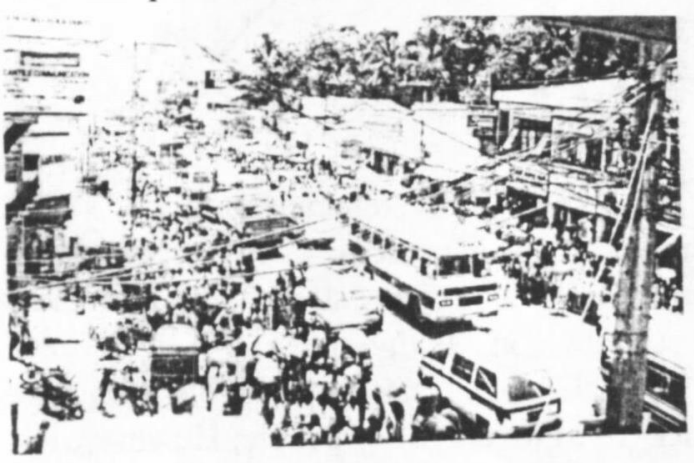

Figure 6: Vehicles, People ands Space Activities

Despite the lack of definitive physical attributes, the Nugegoda stretch has a vibrant array of activities. They are primarily of two fold,

- Walking between the two important transportation nodes 5 . A constant flow

${ }^{5}$ The Nugegoda Bo-tree junction, and the super market junction, are two prominent points from which commuters take busses to different destinations. Thus this space functions as the of people, who intermingle involving also in other activities bringing in social interraction.

- The shopping activities, which brings in crowds from distant places.

This is an example of a place within the town and community, where action seems to concentrate itself to a single location (activity concentration). The perception of the street as a "socially vibrant place" has come into being due to this factor, which has invariably created a dynamic environment within the place. There is a strong continuity and rhythmic variety in the activity mix within the space, which are supportive to each other's presence and continuity.

"Shopping" is an important activity in the formation of socially vibrant places. The urban experience of such places are complex. It is worth nothing that many elements of opposite polarities could exist in urban spaces that sustain this kind of activity. While certain conditions please the urbanites, others (physical arrangements) could frustrate their needs and annoy them. The Nugegoda stretch could be assimilated predominantly as a "social experience on the move", which is at times enhanced and at times hindered by the physical demarcations. The experiences of the "narrow" shop fronts bordering the side walk, is a quick temporal, The close proximity of shops to each other, "accentuates this experience". This is left in the form of. "change in colour and textures" of numerous materials, and items on display.

For example, the "colourful fabrics displayed", some "spilling on the side walk", the assimilation of the Jewellery stores", the varied "colours and textures of the stacked up display of bags", the "smell of food", and the "cooling of the ice-cream parlours". These are all reported to be experienced in a "non-stop tempo" while on the move, "adding vigor and life", to the sensory experience of social life, within

obvious and only link that takes commuters to the two points. 
this urban setting. The entire stretch is said to be a "variation of sensations", and "people in action".

Most meanings generated within the place, are related predominantly to the functional meaning of shopping and transportation. In fact, the symbolic meanings are connected to the manner in which they are performed. Socializing of people engaged in shopping (talking and conveying messages to others etc.) and as Rappoport (1990:19) expresses, "the function of displaying conspicuous consumption, shopping as recreation, and a way for women to get out of the house, all have symbolic meaning embodied within the function itself".

Smaller places come into being within the larger urban context, due to activity pockets created around "smaller centers" (shops, vendors), the placement and zoning of which activities create different social groups. They have meanings, symbolising and indicating status, and social identity, and therefore are not merely locus for manifest activity alone.

Perceptual meanings come into being by all the previously stated sensual cues along the street while associational meanings come into being within the setting among individuals who are engaged in the activity. For example, the shop owners, and vendors, all express strong meanings related to the

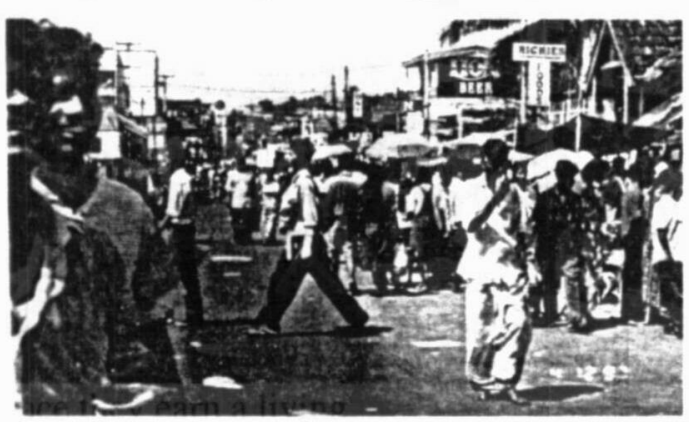

place they earn a living.

Figure 7: Social Experience on the Move In essence, Nugegoda stretch is a significant place in the city primarily made up by the presence of the activity domain itself. The physical attributes indeed are pitifully inadequate and indeed do not enhance the sense of place here in any meaningful way.

\section{Concluding Remarks}

It is clearly established in this study that significant places come about in two predominant ways. In one way, they are brought about by the presence of significant physical elements: "Physically Exotic Places". The presence of the components of the physical world that brings about profound experiential opportunities set the stage for the social drama to unfold. The "unfolding" can indeed transform the place positively. However, they can also bring in negative aspects. These we have not discussed here but "transformation" and "unfolding" are essential processes that need to be cultivated and indeed controlled.

In planned interventions in such places, two significant acts are warrented. On the one hand, those physical elements that contribute profoundly to the place must be carefully enhanced, both individually and collectively. It is necessary to emphasise here that the elements can not be taken individually, but the entire "ballet" of the place must be discovered and sensitively orchestrated. On the other, the "social drama" that unfolds must be supported to be sustained and enhanced. Here, the essential acts must be identified and their anchorage must be made possible. The sequence of activities must be mapped out and their sequence must be facilitated. Above all, a unity between the physical affordances and the intensity of social drama must be enabled so that the place that is already there does not diminish with the onset of the social drama itself.

It is proposed that in situations where the significance of place is primarily a manifestation of the physical attributes, the planned interventions must largely be in the realm of the social order. Intervention in the physical fabric may be needed but this indeed is to subtly enhance its perceptual presence, and formation of opportunities for the social acts. In the social order, it is a way 
of "restraining" while enabling that is needed. Because it is evident in such places that the social acts can overwhelm to the extent that the presence of the place can begin to decline by itself.

In another way places occur by the vibrant presence of social drama itself, even in the midst of unsupportive physical fabric: Socially Vibrant Places. This is indeed what is so abundantly present in our cities where the squalor and lack of order is more the norm than otherwise. "Becoming places" through social drama however is not devoid of physical characterstics that anchor them. In the case study we examined there were a number of significant elements present in the landscape that made it happen. The Botree, the Junction, the stretch and the Supermarket at the other end. These were the physical elements that sustained the social vibrance of the place, and indeed they also generated it. Thus planned intervention in places such as these need actual physical interventions in the planning and design realm, rather than in the social realm. It was noted that the walkways were physically insufficient for the crowds, lacked order and finesse and in fact acted against the social drama that was unfolding. In this, any positive intervention calls for two design acts. One is what can be called the "elimination"; elimination of the obstacles for the place ballet, and the other "assimilation"; assimilation of physical enablers and supportive spatial built forms.

This study is a preliminary attempt to employ the constituents of place to identify the characteristics of significant places. It attempted to deviate from the positivistic stand commonly employed to examine solitary aspects of place and to move towards a phenomenological inquiry that will generate holistic perspectives. Its stance is that the idea of "place" offers insightful understanding of the totality of places as opposed to detailed consclusions about specific aspects of places. It is believed that such an approach can generate insights and understandings that are immediately useful to the designer whose own task is planned interventions in places. This study is expected to provide a theoretical stand and an approach to make such interventions place-sensitive and place enhancing.

\section{Reference:}

Alexander, C (1977) A Pattern Language, Oxford University Press. London.

Canter, D.V (1977) Psychology of Place, London: Architectural Press.

Dayaratne, R (1992) Supporting Peoples Placemaking; Theory and Practice. An Unpublished Doctoral Thesis, University of Newcastle upon Tyne, U.K

Heidegger, M (1980) Being and Time, New York: Harper Row

Meiss, V (1990) Elements of Architecture: From Form to Place, London: Van Nostrand Reinhold

Ralph, E (1976) Place and Placelessness, London: Pion Ltd.

Schultz, N (1980) Genius Loci- Towards a Phenomenology of Architecture, Cambridge:MIT Press.

Tuan, Yi.Fu (1977) Space and Place: the Perspective of Experience, London: Edward Arnold.

Rapoport, A (1990) Human Aspects of Urban Form, Oxford: Pergamon Press.

\footnotetext{
This paper is based on research carried out through a grant offered by NARESA (now called the National Science Foundation of Sri Lanka). Dr. Ranjith Dayaratne is a Senior Lecturer at the University of Moratuwa Sri Lanka and Amanda Rajapakse, was a Final Year Postgraduate student in Architecture.
} 